TAO, Vol. 16, No. 2, 467-485, June 2005

\title{
Site Characteristics of the Puli Area, Taiwan
}

\author{
Huey-Chu Huang ${ }^{1, *}$ and Chau-Rong Tarng ${ }^{1}$
}

(Manuscript received 3 November 2004, in final form 19 April 2005)

\begin{abstract}
It has been widely documented by now that the intensity of the September 21, 1999 Chi-Chi earthquake resulted in severe damage in the Puli area; regrettably, however, only two strong-motion stations (TCU073 and TCU074) had been installed. To investigate the site characteristics of this area, we carry out dense microtremor measurements at 87 sites. The comparisons of the $\mathrm{H} / \mathrm{V}$ ratios between the earthquake recordings and microtremor data at TCU074 strongly indicate that with regard to both trend and predominant frequency, they are highly consistent. Undeniably, what this signifies is that the use of microtremors is, in fact, a good alternate for the study of site effects. We also use the GIS to integrate the results of the $\mathrm{H} / \mathrm{V}$ ratios of the microtremors and the patterns of damage. With the intersection of Chungsan Rd. and Chungcheng Rd. taken as the heart of the town of Puli, we find that the predominant frequencies are at their highest in the center of the town, whereas they are at their lowest in the eastern part. However, we also find relative high predominant frequencies in the range of $2 \mathrm{~Hz}$ to $4 \mathrm{~Hz}$ in the western part of the town which just happens to be the area which was the most seriously devastated by the Chi-Chi earthquake. As for the amplification factors, based on the contours at different frequencies, at frequencies of $2 \mathbf{- 4 ~ H z}$, they are remarkably high in the center of Puli. Besides this, the amplification effects in the northern area where multi-story buildings collapsed are by far the most obvious, with related predominant frequencies between $0.7 \mathrm{~Hz}$ and $0.9 \mathrm{~Hz}$. On these grounds, we conclude that the collapse of many structures during the ChiChi earthquake was very closely related to the site effects of Puli.
\end{abstract}

(Key words: Microtremor measurement, H/V ratio, Predominant frequency, GIS, Amplification factor, Site effect)

\footnotetext{
${ }^{1}$ Institute of Applied Geophysics, National Chung Cheng University, Chia-Yi, Taiwan, ROC

* Corresponding author address: Prof. Huey-Chu Huang, Institute of Applied Geophysics, National Chung Cheng University, Chia-Yi, Taiwan, ROC; E-mail: seihuey@eq.ccu.edu.tw
} 


\section{INTRODUCTION}

That there is a direct causal relationship between local geological conditions affecting ground motion and the devastation from an earthquake is conclusive. Although the best approach to understanding ground conditions is by means of direct observation, such studies are, of course, restricted to areas with relatively high rates of seismicity. Given the many constraints inherent in various methodological approaches, such as the need for high rates of seismicity and the availability of an adequate reference site, a wide range of different techniques has been applied in numerous studies on site response. As reported here, however, in studies which aim to estimate the effects of surface geology on seismic motion, the use of microtremors provides a technique which is invaluable in that it requires no other geological information. In this regard, several previous investigations have been devoted to examining the applicability of microtremors in the evaluation of ground motion characteristics, among the most notable of which are those by Udwadia and Trifunac (1973), Kanai (1983), Field et al. (1990), and Yamanaka et al. (1993).

A technique using horizontal-to-vertical spectral ratios (H/V ratio) of microtremors was first applied by Nogoshi and Igarashi $(1970,1971)$. Recently, the H/V technique (Nakamura 1989) has been gaining increasing popularity since it facilitates data correction and can easily be applied in areas of low or even zero seismicity. The claim has previously been made that the vertical component of ambient noise not only maintains the characteristics of the source to the surface ground of sediments, but also is significantly influenced by Rayleigh waves on the sediments; for these reasons, it can be used to remove both the source and Rayleigh wave effects from the horizontal components. The $\mathrm{H} / \mathrm{V}$ technique is equally as effective in identifying the fundamental resonant frequency of a sedimentary layer, while still determining amplification factors that are more realistic than those obtained from sediment to rock site ratios. Many researchers (e.g., Ohmachi et al. 1991, 1994; Lermo and Chavez-Garcia 1994; Field and Jacob 1993, 1995; Konno and Ohmachi 1995, 1998) have, in fact, shown how such H/V ratios of noise can be used to identify the fundamental resonant frequencies and relative amplification factors of sediments. However, in the authors' opinion, the technique has lacked a rigorous theoretical background until now.

The Chi-Chi earthquake $\left(M_{W}=7.6\right)$ in central Taiwan occurred at $1: 47$ a.m. on September 21, 1999. Triggered by the reactivation of the pre-existing Chelungpu fault, it generated a rupture totaling more than $105 \mathrm{~km}$ in length and a maximum offset of $11 \mathrm{~m}$ (vertical) and $10 \mathrm{~m}$ (horizontal) and caused the greatest number of casualties and the heaviest damage of all recorded natural events in the history of Taiwan. The intensity of the shaking in the central part of the island was extremely high, and extensive soil liquefaction was observed in many areas. While it is true that the Puli area is about $60 \mathrm{~km}$ away from the epicenter (Fig. 1), the large ground shaking caused devastating effects in the center of the town, with many buildings either being seriously damaged or totally collapsing. To understand initially the patterns of destruction in the center right after the Chi-Chi earthquake, we did a detailed investigation in the center on foot. More than 6,000 buildings had partially collapsed, and more than 5000 had completely fallen to pieces, as shown in Fig. 2.

Despite there being only two strong-motion stations (TCU073 and TCU074) deployed in 
the Puli area, to investigate the site characteristics, we make our dense microtremor measurements from 87 observation points distributed in the Puli area. Based on the strong-motion data at TCU074 and the microtremor data from the 87 sites, we analyze site responses using the $\mathrm{H} / \mathrm{V}$ ratio method. In the final stage, we use the Geographic Information System (GIS) to integrate the site characteristics and the patterns of damage in the Puli area. The motivation for this research is our quest to identify the reasons for the factors which gave rise to such extensive damage in the Puli area as a result of the Chi-Chi earthquake.

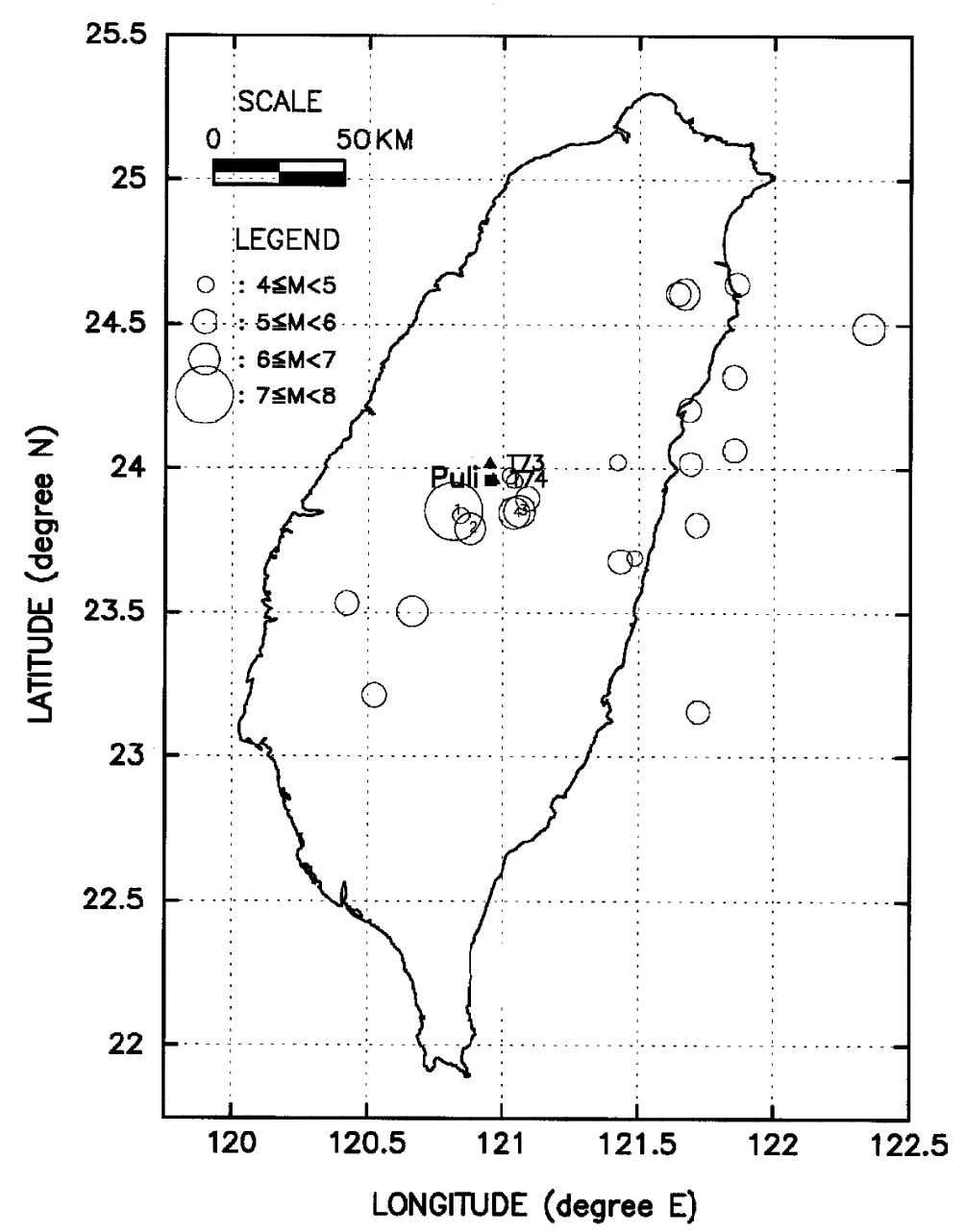

Fig. 1. Location of Station TCU074 (triangular symbol), the reference Station TCU073 (triangular symbol), the epicenter of the Chi-Chi mainshock $\left(M_{W}=7.6\right.$, labeled 1), three Chi-Chi aftershocks (labeled 2, 3 and 4) and 26 weak-motion events (no label) recorded at TCU073 and TCU074. 


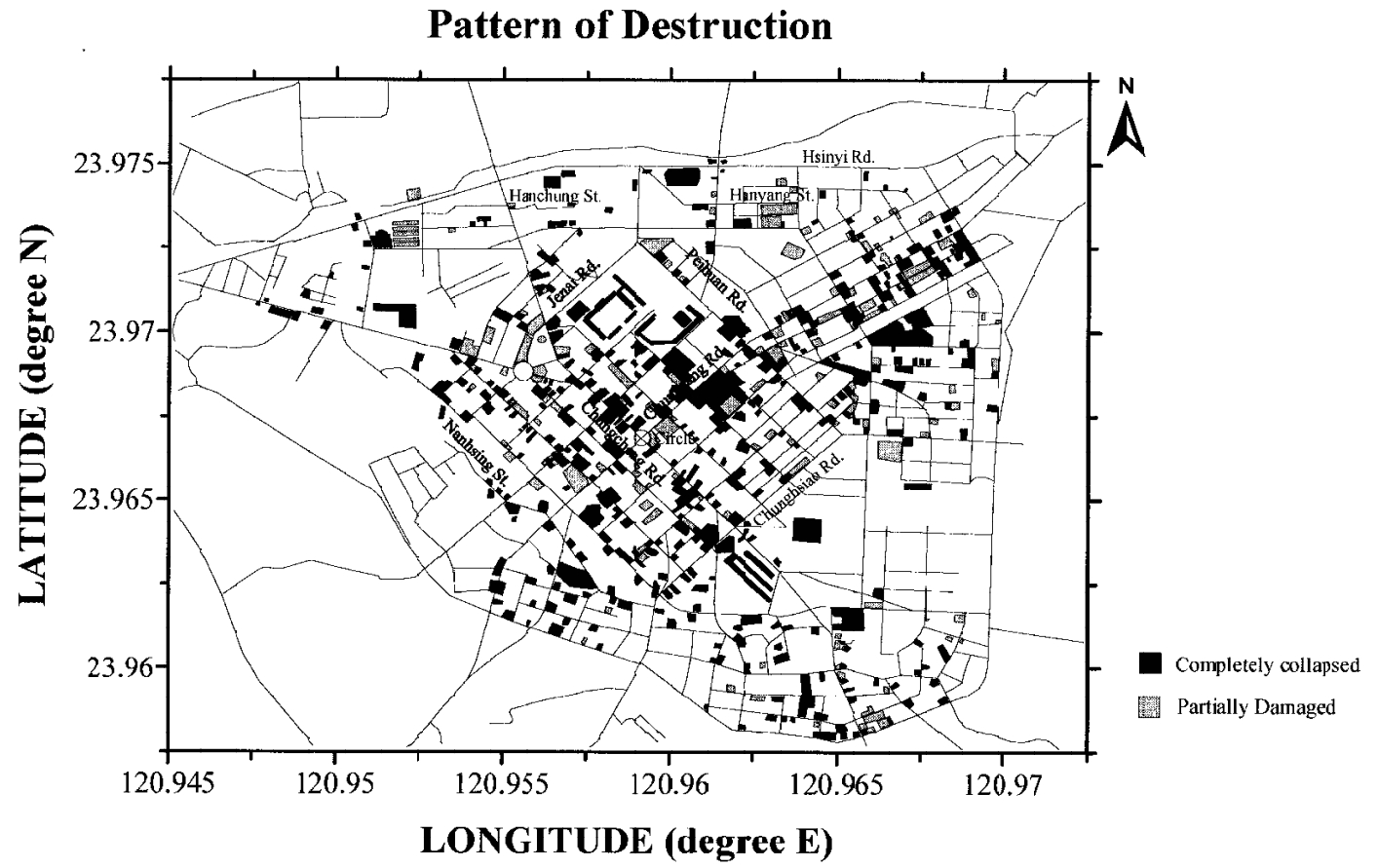

Fig. 2. Patterns of destruction in the Puli area resulting from the Chi-Chi earthquake. More than 6000 buildings partially collapsed, while more than 5000 totally collapsed.

\section{TECHNIQUES}

Site effects, usually considered empirical transfer functions of surficial layers, are commonly studied by employing one of two techniques: the standard spectral ratio or the $\mathrm{H} / \mathrm{V}$ ratio methods. The standard spectral ratio, $S_{T}$, is calculated by dividing the horizontal Fourier spectrum of ground motions on an alluvium site, $S_{H S}$, by that recorded on a nearby rock site, $S_{H B}$. The latter station is taken as the reference station. This means:

$$
S_{T}=\frac{S_{H S}}{S_{H B}} .
$$

Following the work of Nakamura (1989), Lermo and Chavez-Garcia (1993) later used a spectral ratio $E_{S}$ to estimate the amplitude effects of the source. That is:

$$
E_{S}=\frac{S_{V S}}{S_{V B}},
$$


where $S_{V S}$ and $S_{V B}$ are, respectively, the Fourier spectra of the vertical motions on the surface and those on the bedrock at a certain depth. Nakamura (1989) had assumed that the vertical component of the microtremor spectra was not amplified by low-velocity surface layers, and he estimated the effect of Rayleigh waves on the vertical component of tremors by evaluating $E_{S}$. He postulated that if the effects of the Rayleigh waves were the same on the vertical and horizontal components, then $E_{S}$ could be used to eliminate the effects of Rayleigh waves on the transfer function. In applying this theory to compensate for the source effects $\left(E_{S}\right)$, Lermo and Chavez-Garcia (1993) introduced a modified site effect function $\left(S_{T T}\right)$, namely:

$$
S_{T T}=\frac{S_{T}}{E_{S}}
$$

which is equivalent to:

$$
S_{T T}=\left(\frac{S_{H S}}{S_{V S}}\right) /\left(\frac{S_{H B}}{S_{V B}}\right) .
$$

From microtremor measurements in a borehole, Nakamura (1989) also determined that the ratio, $S_{H B}: S_{V B}$, was nearly $1: 0$. More recently, Huang and Teng (1999) examined the ratio using microtremors and earthquake recordings at a bedrock site in Chiawan, Taiwan and found it to be nearly $1: 1$. In light of these empirical findings, we assume here that a reasonable estimate of the modified site effect function can be determined from:

$$
S_{T T}=\frac{S_{H S}}{S_{V S}}
$$

This demonstrates that the $\mathrm{H} / \mathrm{V}$ ratio, as defined by this transfer function, can be obtained solely from the motions on the surface, which obviously makes it easier to estimate the characteristics of ground motion. Put briefly, in this paper, we study the site characteristics of the Puli area using the $\mathrm{H} / \mathrm{V}$ of microtremors.

\section{GEOLOGY}

Located in central Taiwan, Puli is a structural basin which is the downcast area of a Tertiary submetamorphic rock mountain. Figure 3 shows the geological map and the geological section along line AA' near Puli (Huang et al. 2000). Owing to numerous faults and folds, Puli became a low-lying basin, and as a result of deposits, meanders, erosion and rejuvenation, the lake in the midst of the mountains later dried up. Presently, nearby rivers continue to erode the terrain. By and large, these are the factors which account for the geological features of the Puli basin. 


\section{Geology in the Puli Area}
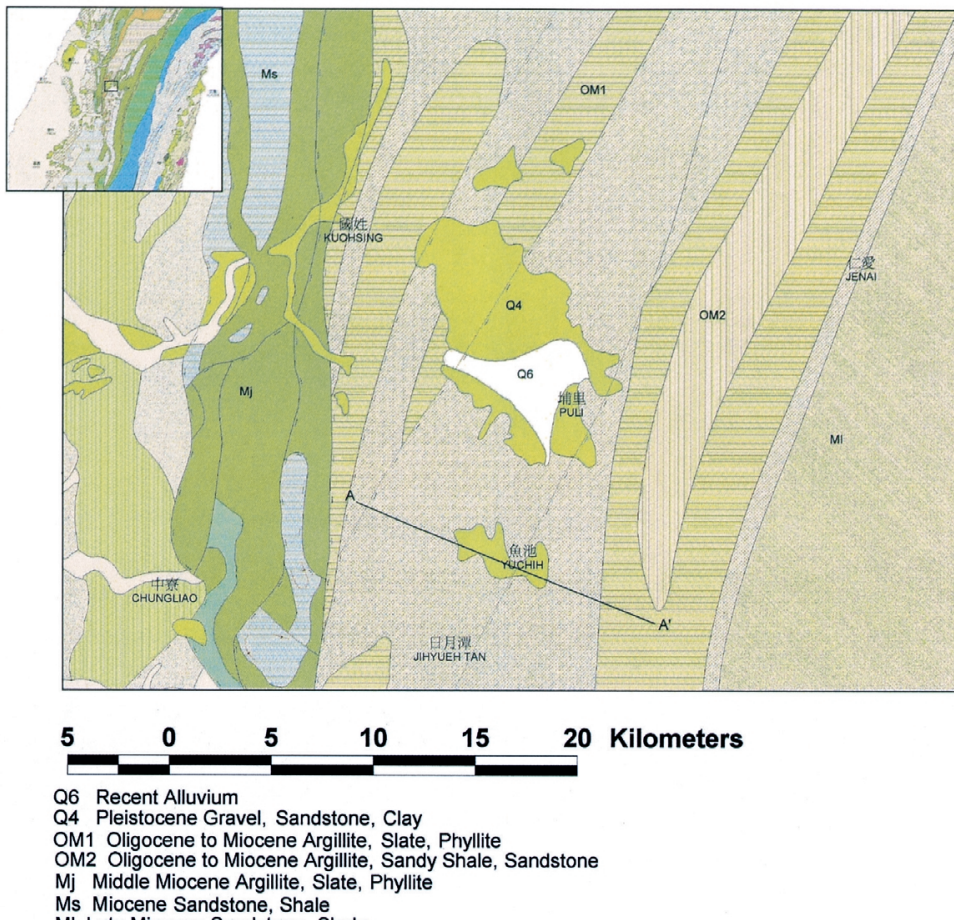

Mj Middle Miocene Argillite, Slate, Phyllite

Ms Miocene Sandstone, Shale
MI Late Miocene Sandstone, Shale

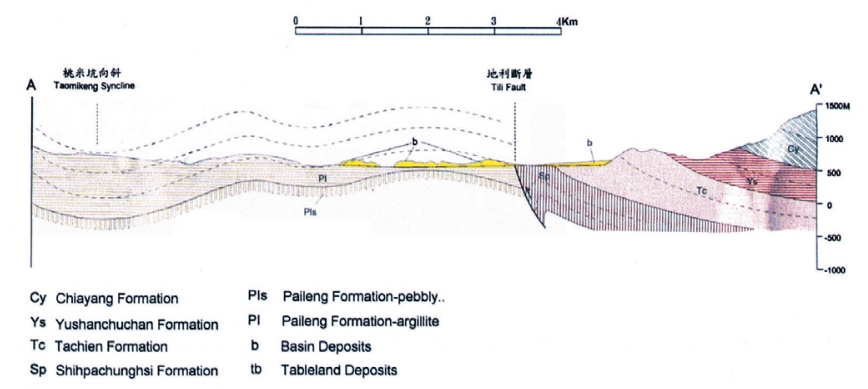

Fig. 3. Map sketching the geology of the Puli area and the geological section along line AA' near Puli (revised from Huang et al. 2000).

Figure 4 shows a 3D vertical view near the Puli basin. When the Nankanhsi cuts through the Yuchih basin and enters the Puli basin, it combines with the Taomihsi on the left and then joins the Meihsi located on the western side of the basin. In the southwest and in the northern boundary zone of the Puli basin, stream terraces are found. In the western part of the Puli basin, flat smooth hills and spacious valleys which have suffered from strong weathering predominate. The surface of the layers is covered with laterite. All of this indicates that the geology of this area had already developed in the old stage. 
Apart from this, inside the Puli basin, except for some sections which are terrace deposits and river alluvium, most sections are basin deposits. At a depth of $50 \mathrm{~m}$ in the Meihsi and the Nankanhsi, most rocks are composed of conglomerates, which, in their thickest parts, often exceed $100 \mathrm{~m}$ in depth. The basin is mostly comprised of recent alluvium which, from the top down, can be divided into five sublayers: (a) alluvium; (b) tableland deposit conglomerate; (c) Toukoshan formation conglomerate; (d) Toukoshan formation clay; and (e) Tertiary basement.

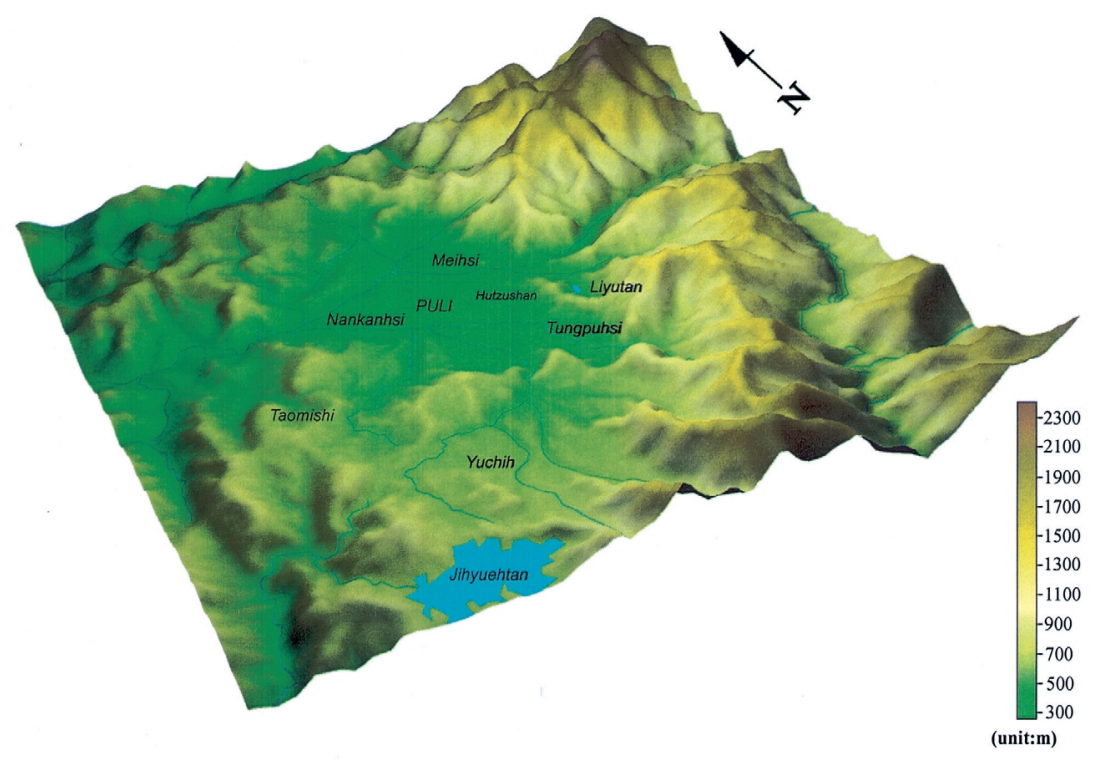

Fig. 4. Three-dimensional vertical geographic view of the Puli basin.

\section{DATA AND SITES}

A dense strong-motion observation network was set up by the Central Weather Bureau (CWB) roughly ten years ago, and while it consists of some 150 stations (named TCUxxx with $\mathrm{xxx}$ representing the station number) in the central part of Taiwan, unfortunately, only two, TCU073 and TCU074, are located in the Puli area. When the Chi-Chi earthquake $\left(M_{w}=7.6\right)$ struck central Taiwan, the town of Puli in Nantou County suffered extensive damage, particularly to its settlements, the inclination of its buildings and its infrastructure. The PGA values triggered by the Chi-Chi earthquake at Station TCU074 were 368/270/586 gals, but regrettably, a malfunction occurred at Station TCU073.

Since the Chi-Chi earthquake produced many reliable strong motion data sets, here we are able to compare the site responses of strong-motion events with those of some weak-motion events previously recorded at TCU074 during the 1993 - 1998 period. Figure 1 shows the epicenter of the Chi-Chi (921) mainshock (marked with a circle and "1"), three Chi-Chi aftershocks ( $M_{L} \geq 6.5$, labeled 2, 3 and 4) and some of the weak-motion events recorded at TCU074 and TCU073 used here. For the assessment of the site responses, we extract the intense 
S waves with a cosine taper at a 20 -sec length for the Chi-Chi mainshock and at a 10 -sec length for all other ground motions. To prevent the occurrence of pseudopeaks caused by spectral holes, we use the $0.25 \mathrm{~Hz}$ Hanning smoothing technique in our $\mathrm{H} / \mathrm{V}$ ratio calculations.

Nevertheless, with only two strong-motion stations deployed in the Puli area, to investigate the relationship between the site characteristics and the distribution of earthquake damage in and around Puli, it is necessary to perform dense microtremor measurements at 87 observation points distributed in Puli and its vicinity using a hand-type seismocorder system (SPC-51) along with three-component velocity sensors VSE-15D with a sensitivity range of $0.07 \sim 100 \mathrm{~Hz}(-3 \mathrm{~dB})$. Based on the distribution of the collapsed buildings and the brokendown infrastructure in the Puli area, we choose 87 measurement sites made up of 79 points in the town of Puli itself, 6 sites in the outlying area and 2 sites close to the strong-motion stations, i.e., TCU073 to the north of Puli and TCU074 in Puli itself. Figure 5 shows the location of the 87 measured points, named PUL001 PUL087.

We record velocity data at the rate of 200 samples per second on a permanent 16-bit, 16-channel data acquisition system. At each observation point, we continuously record microtremor measurements for about thirty minutes, and we divide the records into several 40 -sec segments by using a 20-point cosine taper. Besides this, there is a $50 \%$ overlap between any two neighboring 40-sec segments, but we delete all microtremor data with strong noise. We calculate the Fourier spectra for all segments we use and then smooth the spectra by using a $0.25 \mathrm{~Hz}$ Hanning window. In the next stage, we compute the spectral ratios between the horizontal and vertical components and finally compute the average of the individual $\mathrm{H} / \mathrm{V}$ ratios.

\section{RESULTS AND DISCUSSIONS}

\subsection{Comparison of Strong- and Weak-Motion Events}

Based on the high-quality, strong-motion recordings, we first examine the results from the $\mathrm{H} / \mathrm{V}$ ratio method by comparing them with those from the traditional spectral ratio method. The H/V ratios (thick lines) at Station TCU074 (a soil site) and the spectral ratios (TCU074/ TCU073, thin lines) are shown in Fig. 6. We select Station TCU073 as the reference site, and the results we obtain using the $\mathrm{S}$-wave windows for the weak-motion events are shown in Fig. 1.In essence, the predominant frequencies estimated from both methods are strikingly close at about $1.4 \mathrm{~Hz}$, and beyond this, their trends are also similar. Most assuredly as a response to the ChiChi mainshock, the PGA values at most of the strong-motion stations are larger than those recorded during the earlier 1993 - 1998 period. We also compare the site responses between the strong- and weak-motion events at Station TCU074. Figure 7 compares the averaged H/V ratios of the Chi-Chi mainshock (thin lines), the Chi-Chi aftershocks (thin dotted lines) and the weak-motion events (thick lines) at Station TCU074. These PGA values, triggered by the mainshock, are larger than $0.58 \mathrm{~g}$. Unlike those of the weak-motion events, the predominant frequency of the Chi-Chi mainshock (a strong-motion event) shifts to a lower value. This most likely implies that the site was characterized by nonlinear behavior at the time of the Chi-Chi earthquake. 


\subsection{Microtremor Measurements}

With the aim of investigating the relationship between the site characteristics and the distribution of damage caused by the Chi-Chi earthquake in Puli, as stated earlier, we perform dense microtremor measurements at the 87 sites distributed in the center of Puli and in the neighboring area (Fig. 5). Because post-Chi-Chi earthquake building reconstruction was ongoing in the Puli area, there were many sources of noise when the microtremor measurements were being taken in April 2001. Thus, we do not use the microtremor data with strong noise in our sample. In all, to analyze the site characteristics of the Puli area, we are finally able to use microtremor data from 72 sites.

In line with Huang (2002), comparing the patterns of the predominant frequencies of the microtremor data and those of the earthquake recordings, we find them to be similar at most stations although the amplification factors we estimate from the microtremor data show lower values. Similar results appear at TCUxxx stations. We then compare the H/V ratios between the earthquake recordings and the microtremor data at TCU074. In Fig. 8, the predominant frequencies that we individually estimate from the microtremor and earthquake data are simi-

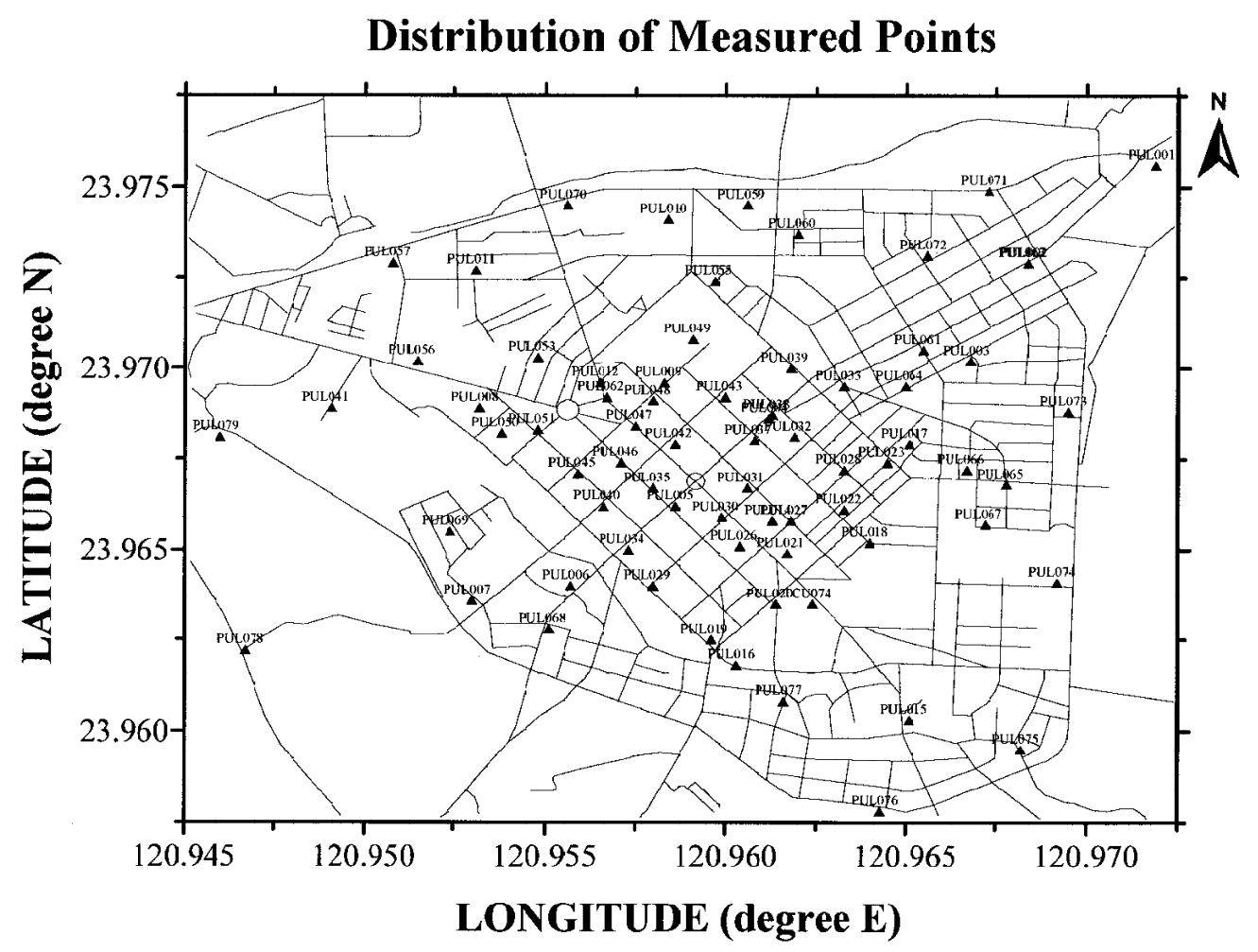

Fig. 5. Location distribution of the 87 measured points referred to as PUL001 PUL087. 


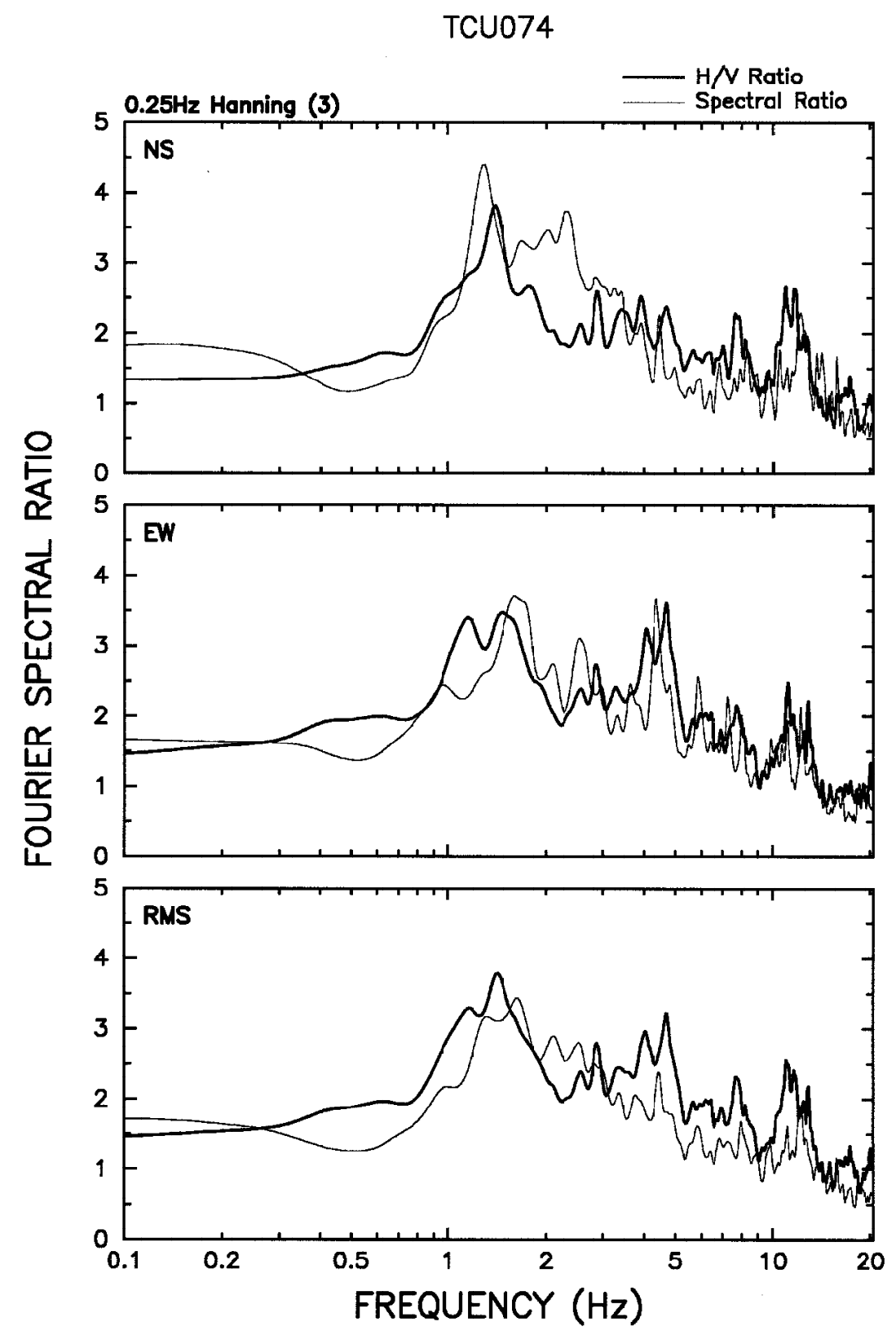

Fig. 6. Comparison of the averaged H/V ratios (thick lines) at TCU074 and the averaged spectral ratios (thin lines, TCU074/TCU073). TCU073 is selected as the reference station. The three panels represent the NS and the EW components and their corresponding RMS results. The results from the two methods are similar. 


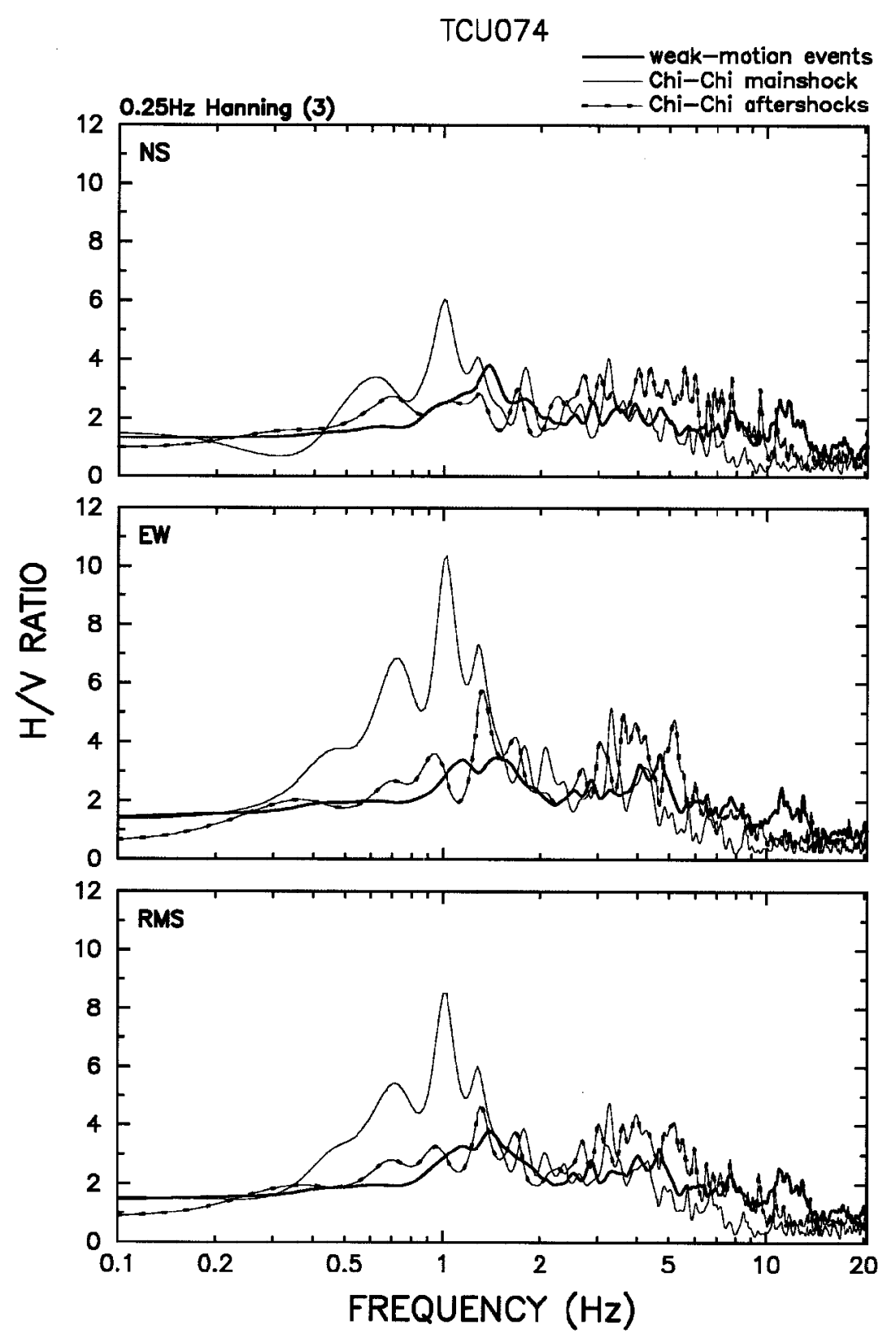

Fig. 7. Comparison of the averaged $\mathrm{H} / \mathrm{V}$ ratios of the Chi-Chi mainshock (thin lines), the Chi-Chi aftershock (thin dotted lines) and the weak-motion events (thick lines) at Station TCU074. The predominant frequencies caused by the Chi-Chi mainshock shifts to lower values when compared with those of weak motions. 


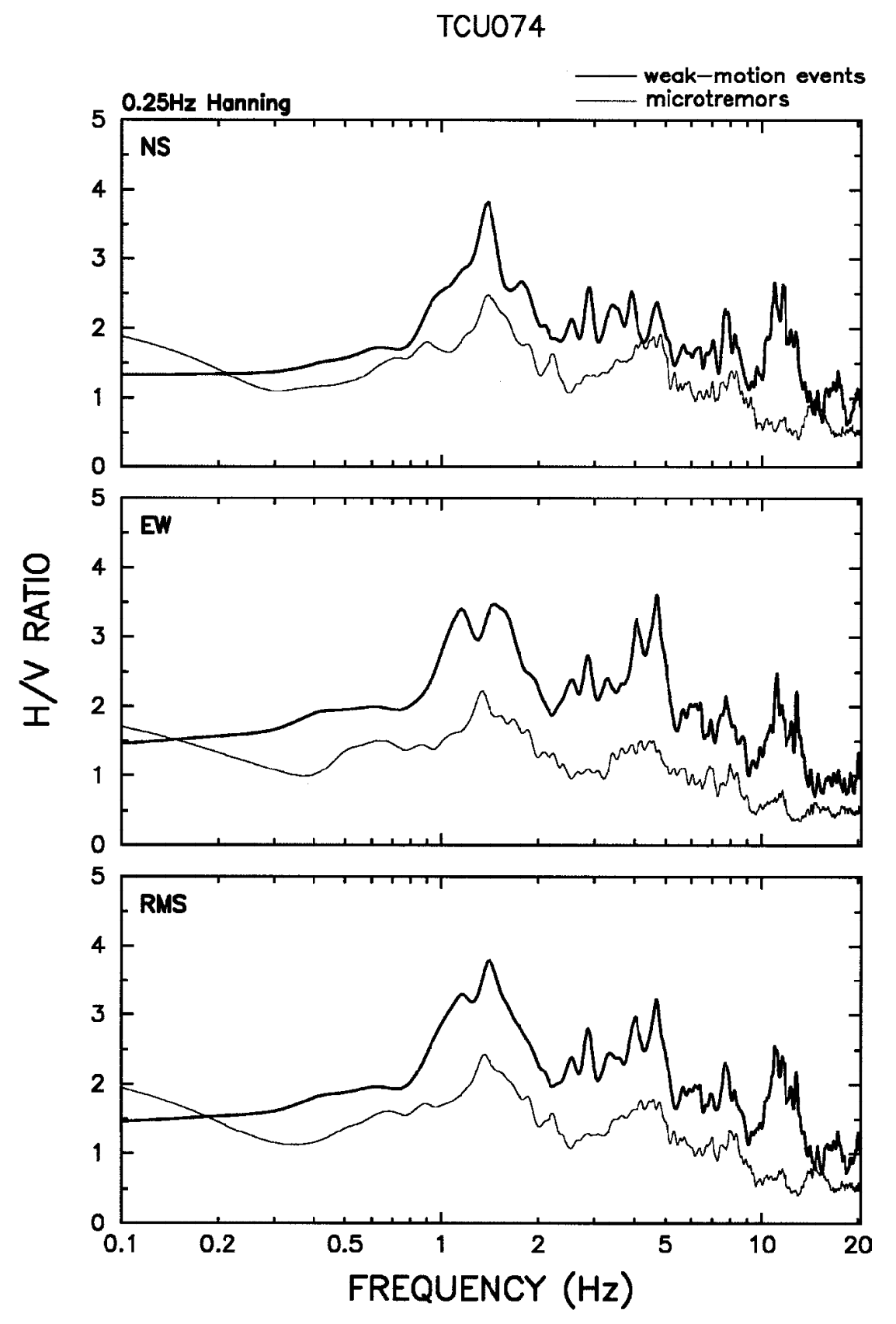

Fig. 8. Comparison of the averaged $\mathrm{H} / \mathrm{V}$ ratios between the microtremor data (thin lines) and the weak-motion events (thick lines) at Station TCU074. 
lar at about $1.4 \mathrm{~Hz}$ although the amplification factors of the microtremor data are underestimated by about a factor of $0.5 \sim 0.8$ between 0.2 and $10 \mathrm{~Hz}$. Undoubtedly, this is a strong indicator that the $\mathrm{H} / \mathrm{V}$ ratios of the microtremors can reasonably predict the predominant frequencies and the relative levels of site amplification. This highly suggests that the use of microtremors serves as a good alternate for the study of site effects in the Puli area.

To further enhance our understanding of the site characteristics of the Puli area, we compute the H/V ratios of the microtremors at the 72 measured points. The predominant frequencies estimated from the Root Mean Square (RMS) results of the H/V ratios at these points are shown in Fig. 9 where different symbols represent sites with different predominant frequencies. There are 18 sites with $f_{p}$ lower than $1 \mathrm{~Hz}, 19$ sites with $f_{p}$ between 1 and $1.5 \mathrm{~Hz}, 8$ sites with

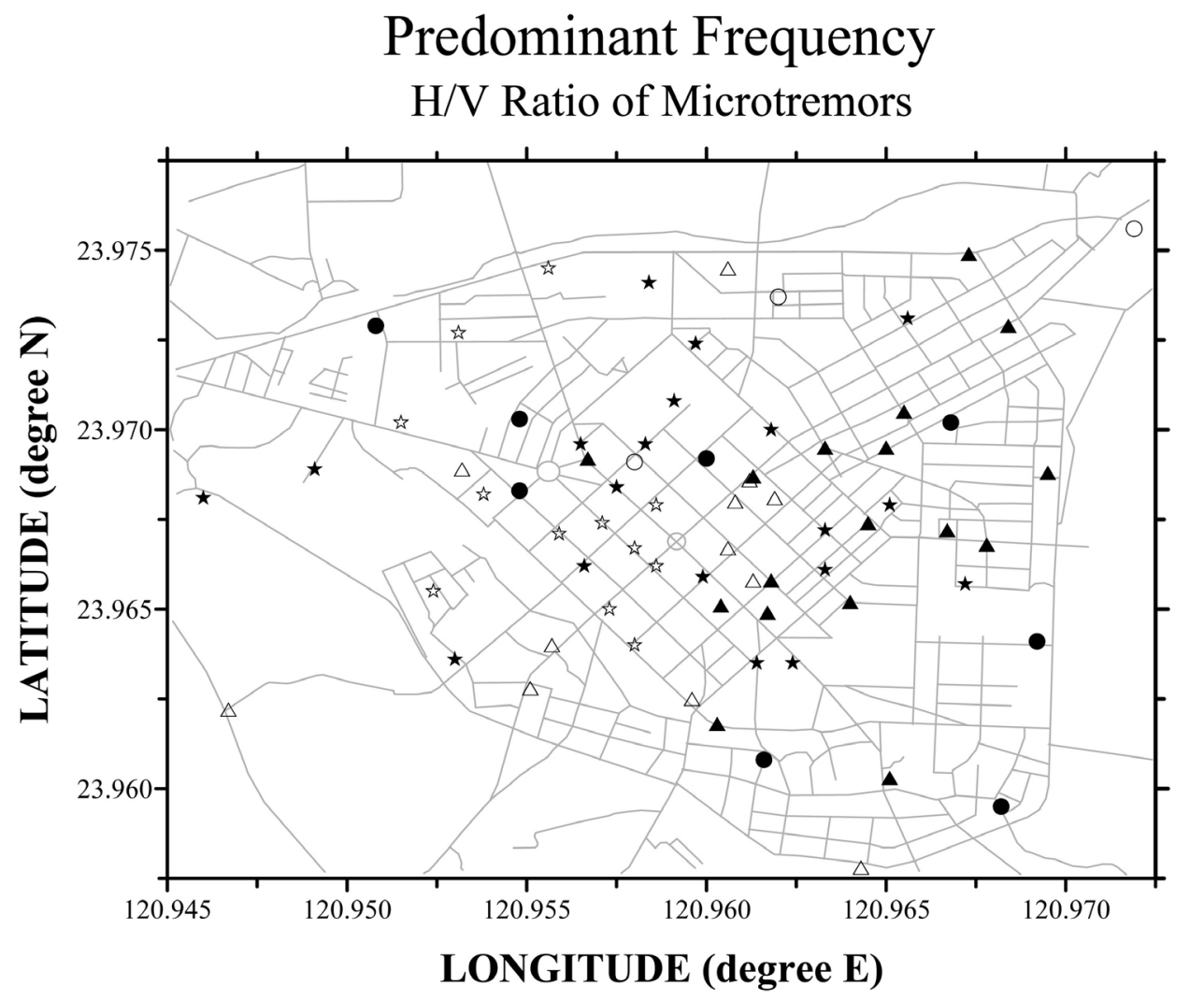

Fig. 9. Distribution map of the predominant frequencies estimated by the averaged $\mathrm{H} / \mathrm{V}$ ratios of the microtremors at the 72 measured points. The different symbols represent those sites with different predominant frequencies, where $\mathbf{\Lambda}$ has $f_{p}$ lower than $1 \mathrm{~Hz}$; has $f_{p}$ between 1 and $1.5 \mathrm{~Hz}$; has $f_{p}$ between 1.5 and $2 \mathrm{~Hz} ; \Delta$ has $f_{p}$ between 2 and $3 \mathrm{~Hz}$; thas $f_{p}$ between 3 and $5 \mathrm{~Hz}$; and $\mathrm{O}$ has no obvious predominant frequency. 
$f_{p}$ between 1.5 and $2 \mathrm{~Hz}, 12$ sites with $f_{p}$ between 2 and $3 \mathrm{~Hz}, 12$ sites with $f_{p}$ between 3 and $5 \mathrm{~Hz}$, and 3 sites with no obvious predominant frequency.

Figure 10 is a contour map of the predominant frequencies from the $\mathrm{H} / \mathrm{V}$ of the microtremors in the Puli area. We also use the GIS to integrate the results of the H/V ratios of the microtremors and the patterns of damage (Fig. 2). On the condition that the intersection of Chungsan Rd. and Chungcheng Rd. is considered the exact center of the town of Puli (as indicated by the circle), the predominant frequencies in the western part of Puli are much higher than those in the eastern part. These considerably higher predominant frequencies between $2.6 \mathrm{~Hz}$ and $4 \mathrm{~Hz}$ are represented by the "Ц"'-shaped symbol. Important to note is that these areas with considerably high predominant frequencies are also those that were the most seriously damaged during the Chi-Chi earthquake. As a rule of thumb, nevertheless, the predominant frequencies are at their

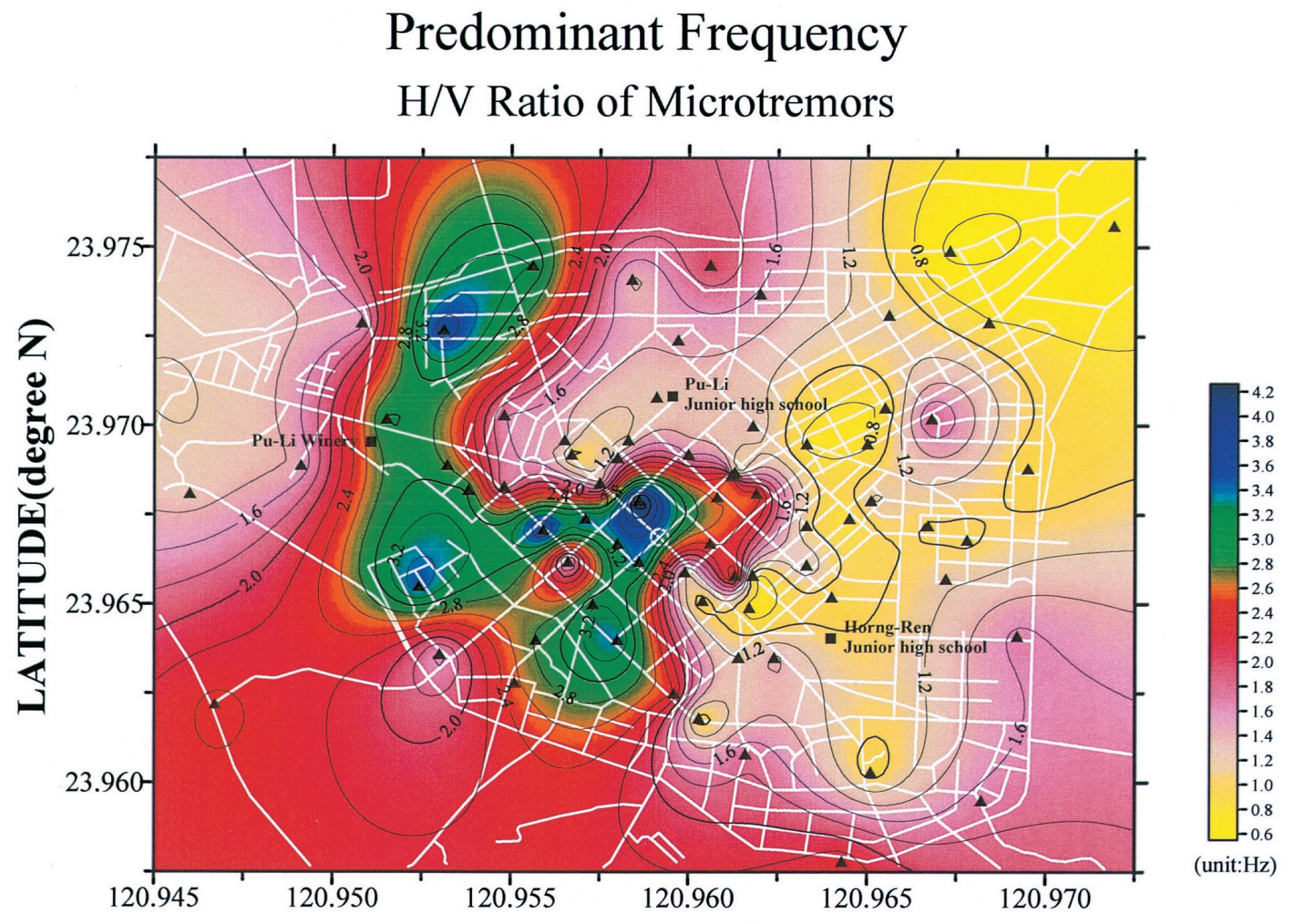

LONGITUDE (degree E)

Fig. 10. Contour map of the predominant frequencies in the Puli area. The small dark triangular symbols represent the stations used. The higher predominant frequencies appear in the center of the town. 
very highest in the very center of Puli, while they are at their very lowest in the eastern part. Frequencies between these two extremes are found in the western part.

The topography of the Puli basin is higher in the east than in the west (Fig. 4), with about an $80 \mathrm{~m}$ difference between the highest and lowest points. Also found are alluvial fans formed by the rivers which flow into the basin, especially the Nankanhsi and Meihsi. Since alluvial deposits from the Xueshan Range came down in torrents from the east to the west in the early years, the eastern part of the Puli basin has thicker alluvium than does the western part. Likely as a result of this, the predominant frequencies in the eastern part of the Puli area are much lower than those in the western part (Fig. 10).

Figure 11 is a contour map of the amplification factors of the predominant frequencies based on the $\mathrm{H} / \mathrm{V}$ of the microtremors in the Puli area. The southeastern part has considerably high amplification factors, but fortunately, few buildings had been constructed there. The western

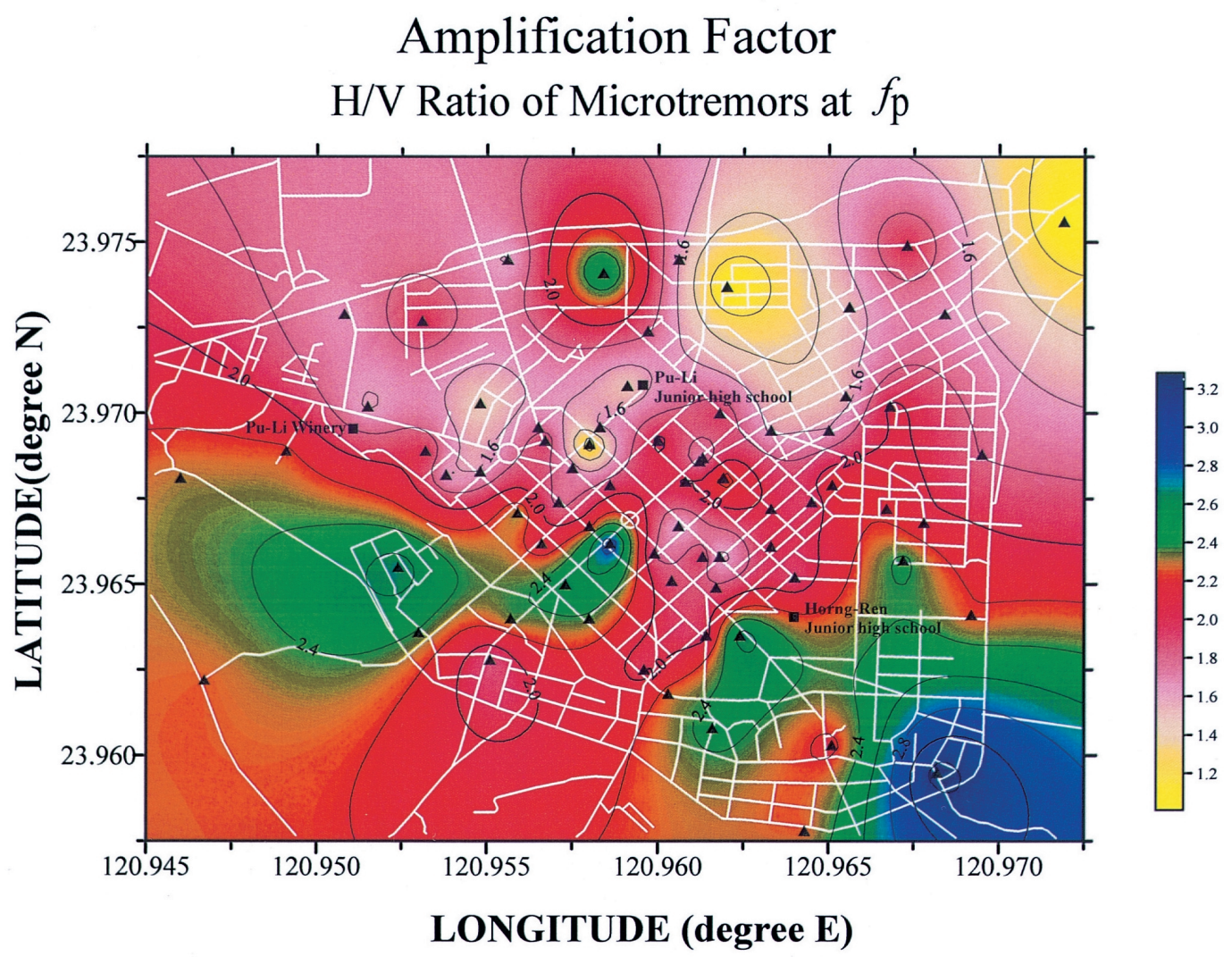

Fig. 11. Contour map of the amplification factors of the predominant frequencies in Puli. The small dark triangular symbols represent the stations used. The higher amplification factors appear in the southeastern area of Puli and in the central area. 
area, meanwhile, also has relatively high amplification factors and, most strikingly, it corresponds with the area that experienced the most serious damage.

Figure 12 shows a contour map of the amplification factors at the frequencies of 0.5, 0.7, 1.0, 2.0, 3.0 and 4.0 Hz in Puli. According to Liao (2000), the fundamental oscillation period of a 12-floor reinforced concrete (RC) structure is about $1.4 \mathrm{sec}($ or $0.71 \mathrm{~Hz})$ in Taiwan. From

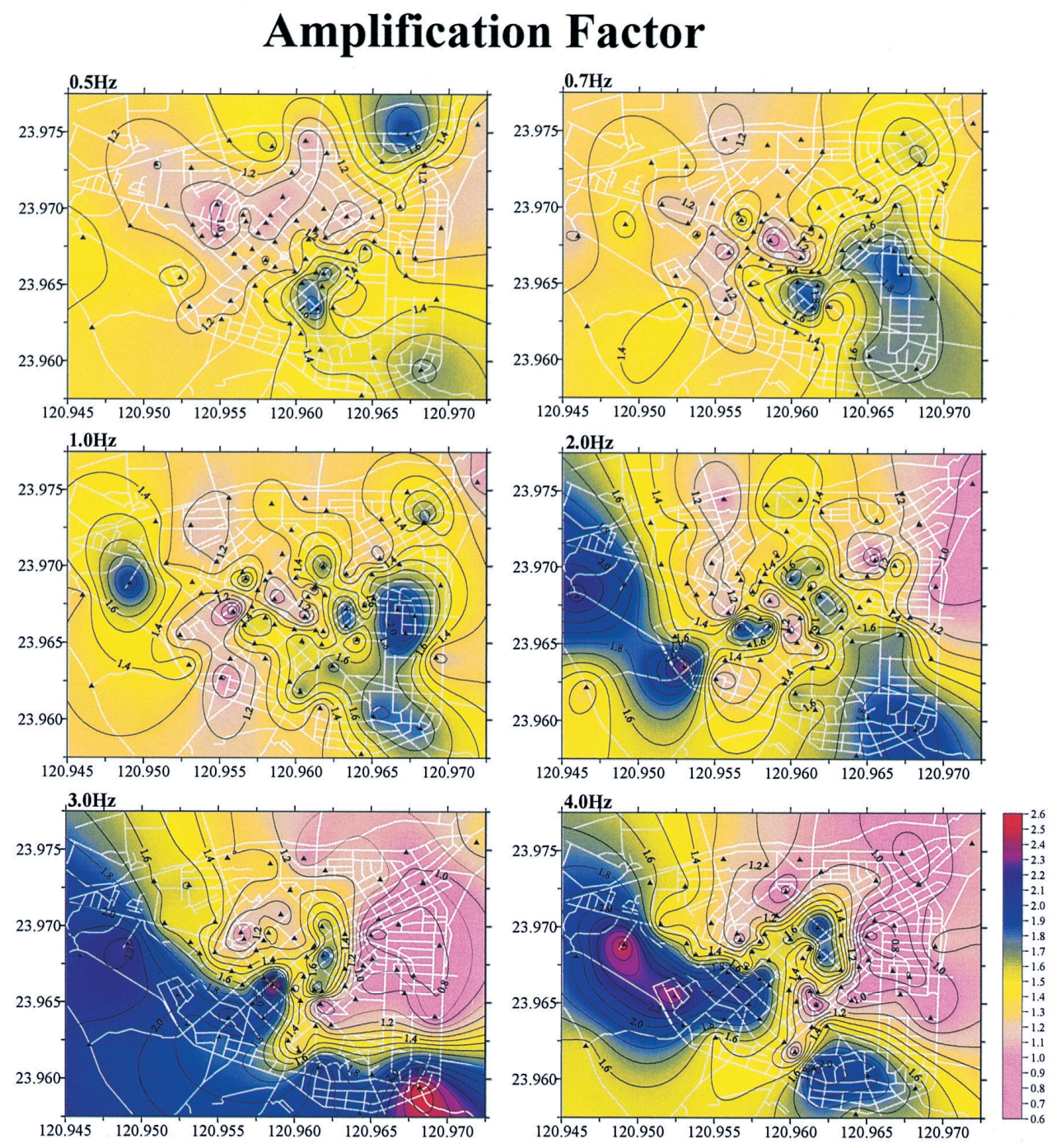

Fig. 12. Contour map of the amplification factors at the frequencies of 0.5, 0.7, 1.0, 2.0, 3.0 and $4.0 \mathrm{~Hz}$ in Puli. The small dark triangular symbols represent the stations used. 
this, we can generally be sure that ground motion with a predominant period of about $0.3 \mathrm{sec}$ (or $3.3 \mathrm{~Hz}$ ) would have had a great effect on a 3-floor building. In the center of Puli, the rectangular region demarcated by Jenai Rd., Nanhsing St., Chunghsiao Rd. and Peihuan Rd. was the area which experienced the greatest devastation during the Chi-Chi earthquake (Fig. 2). The 3- to 4- floor buildings which collapsed there were mostly small shops and offices, and as shown in Fig. 12, the high amplification factors with frequencies of $2-4 \mathrm{~Hz}$ prevail in this area. Against this, several 12-floor buildings that completely or partially collapsed with fatal consequences were situated along Hsinyi Rd., Hanchung St. and Hanyang St. to the north of Puli where the amplification factors were relatively high at between 0.7 and $1.0 \mathrm{~Hz}$. This definitively illustrates the close relationship between the destruction of buildings and the site characteristics of these areas.

However, the results shown in Figs. 11, 12 do not correspond with the destruction in the NE section of the town that is indicated in Fig. 2. In fact, the serious extent of the damage to the buildings may have been partly attributed to many additional factors, including the age of the buildings, the building code specifications, the quality of the materials and construction, the architectural design, the height and the location of the buildings, the intensity of the earthquake notwithstanding. It is evident from these findings, just the same, that the site effects are, indeed, the fundamental factor for the destruction in Puli.

\section{CONCLUSIONS}

The Chi-Chi earthquake induced tremendous and continuing shaking and brought heavy damage to the Puli area of Taiwan. With this in mind, we study the relationships between the spectral characteristics of strong motions, weak motions and microtremors in the Puli area. Since 1991, a wealth of high-quality seismic data has been recorded by the strong-motion observation network of the CWB. In that there are only two strong-motion stations (TCU073 and TCU074) in the Puli area, in our investigation of site responses, we select data sets covering the 921 Chi-Chi mainshock $\left(M_{w}=7.6\right)$, the Chi-Chi aftershocks $\left(M_{L} \geq 6.5\right)$ as well as some weak-motion events recorded during the 1993-1998 period. Additionally, in order to look into the site characteristics of this area, we carry out dense microtremor measurements at 87 sites in the area of Puli.

As the reference station TCU073 did not receive any Chi-Chi earthquake sequences, locating a rock site to serve as a reference station could have presented a serious obstacle. However, to overcome this, we are able to estimate the site response using the $\mathrm{H} / \mathrm{V}$ technique. Its validity is substantiated by the fact that when compared with the results from the conventional spectral ratio method, the predominant frequencies are in very good agreement. Hence, it is reasonable to assume that the $\mathrm{H} / \mathrm{V}$ technique serves as an excellent alternate for site response estimates here. The site characteristics between the strong-motion events and weak-motion events are different, which strongly implies that the nonlinear effects most likely occurred with the strongmotion events. Also worth noting is that the main peak in the $\mathrm{H} / \mathrm{V}$ spectra of the microtremors fits well with the first peak obtained from the weak-motion data, albeit with a considerably different amplification. In short, in this study, when compared to weak ground motion data, 
microtremors are able to predict the predominant frequencies more accurately than the amplification factors of surface motions.

Based on the $\mathrm{H} / \mathrm{V}$ ratios of the microtremors, the predominant frequencies in the western part of the Puli area are higher than those in the eastern part. We use the GIS to integrate the results of the $\mathrm{H} / \mathrm{V}$ ratios of the microtremors and the patterns of damage. Given that the intersection of Chungsan Rd. and Chungcheng Rd. is taken as the heart of Puli, the predominant frequencies in the western part, which covers the most severely damaged area, are higher with a range of $2.6 \mathrm{~Hz}$ to $4 \mathrm{~Hz}$ and are "Ц" -shaped. During the Chi-Chi earthquake, the rectangular region, demarcated by Jenai Rd., Nanhsing St., Chunghsiao Rd. and Peihuan Rd. in the center of Puli, was the most devastated area, and most of the buildings that collapsed there were about 3 - 4 stories high. Turning to the contours of the amplification factors at the frequencies of 2.0, 3.0 and $4.0 \mathrm{~Hz}$, we find that they are astonishingly high in central Puli. Aside from this, the amplification effects in the area with the once multi-story buildings are most apparent, and the relative predominant frequencies are between $0.7 \mathrm{~Hz}$ and $0.9 \mathrm{~Hz}$. Hence, we feel fully justified in drawing the conclusion that the collapse of many structures during the Chi-Chi earthquake was closely related to the site effects in the Puli area although the amplification effects of the microtremors are not consistent with the destruction in the NE section of the town. Here the microtremor results do not provide the perfect answer to the ground motion amplification estimates, but it is still a good alternate for the study of site responses, especially for a site lacking earthquake recordings.

Acknowledgements The authors would like to express their thanks to Dr. T. M. Chang and an anonymous reviewer for their valuable suggestions. They also thank Professors H. C. Chiu and K. L. Wen for stimulating discussions and helpful criticism. In addition, they appreciate the efforts of Mr. C. W. Kao and Mr. Y. R. Chiu for the microtremor measurements in the field. Moreover, they are grateful to Mr. Y. R. Chiu who also provided valuable assistance with plotting. The authors also extend their gratitude to the Central Weather Bureau for providing the strong motion data. The National Science Council, Taiwan, has supported this research (NSC 90-2119-M-194-005).

\section{REFERENCES}

Field, E. H., S. E. Hough, and K. H. Jacob, 1990: Using microtremors to assess potential earthquake site response: a case study in Flushing Meadows, New York City. Bull. Seism. Soc. Am., 80, 1456-1480.

Field, E. H., and K. H. Jacob, 1993: The theoretical response of sedimentary layers to ambient seismic noise. Geophys. Res. Lett., 20, 2925-2928.

Field, E. H., and K. H. Jacob, 1995: A comparison and test of various site response estimation techniques, including three that are non reference-site dependent.Bull. Seism. Soc. Am., 85, 1127-1143.

Huang, C. S., K. S., Shea, and M. M., Chen, 2000: Explanatory text of the geological map of Taiwan (Pu-Li, scale 1:50,000, sheet 32), Central Geol. Surv.. (in Chinese) 
Huang, H. C., and T. L. Teng, 1999: An evaluation on H/V ratio vs. spectral ratio for site response estimation using the 1994 Northridge earthquake sequence. Pure Appl. Geophys., 156, 631-649.

Huang, H. C., 2002: Characteristics of Earthquake Ground Motions and the H/V of Microtremors in the Southwestern Part of Taiwan. Earthquake Eng. Struct. Dyn., 31, 1815-1829.

Kanai, K., 1983: Engineering Seismology, Univ. Tokyo Press Tokyo.

Konno, K., and T. Ohmachi, 1995: A smoothing function suitable for estimation of amplification factor of the surface ground from microtremor and its application.J. JSCE, 525, I33, 247-259. (in Japanese with English abstract)

Konno, K., and T. Ohmachi, 1998: Ground-motion characteristics estimated from spectral ratio between horizontal and vertical components of microtremor. Bull. Seism. Soc. Am., 88, 228-241.

Lermo, J., and F. J. Chavez-Garcia, 1993: Site effect evaluation using spectral ratios with only one station. Bull. Seism. Soc. Am., 83, 1574-1594.

Lermo, J., and F. J. Chavez-Garcia, 1994: Are microtremors useful in site response evaluation? Bull. Seism. Soc. Am., 84, 1350-1364.

Liao, W. Y., 2000: The dynamic response analysis of the RC structure induced by a near fault earthquake. Report NCREE, 34, 1-4. (in Chinese)

Nakamura, Y., 1989: A method for dynamic characteristic estimation of subsurface using microtremor on the ground surface. QR RTRI, 30, 25-33.

Nogoshi, M., and T. Igarashi, 1970: On the propagation characteristics of microtremors. $J$. Seism. Soc. Japan, 23, 264-280 (in Japanese with English abstract).

Nogoshi, M. and T. Igarashi, 1971: On the amplitude characteristics of microtremors.J. Seism. Soc. Japan, 24, 24-40. (in Japanese with English abstract)

Ohmachi, T., Y. Nakamura, and T. Toshinawa, 1991: Ground motion characteristics in the San Francisco Bay area detected by microtremor measurements. Proc. 2nd. Int. Conf. on Recent Advances in Geotech. Earth. Eng. \& Soil Dyn., Saint Louis, Missouri, 11-15 March, 1643-1648.

Ohmachi, T., K. Konno, T. Endoh, and T. Toshinawa, 1994: Refinement and application of an estimation procedure for site natural periods using microtremor. J. JSCE, 489, I-27, 251-261. (in Japanese with English abstract)

Udwadia, F. E., and M. D. Trifunac, 1973: Comparison of earthquake and microtremor ground motions in El Centro, California. Bull. Seism. Soc. Am., 63, 1227-1253.

Yamanaka, H., M. Dravinski, and H. Kagami, 1993: Fundamental characteristics of long period microtremors as observed in the Los Angeles metropolitan area.Bull. Seism. Soc. Am., 83, 1595-1609. 